\title{
FORMAÇÃO DE PROFESSORES PARA TRABALHO COM EDUCAÇÃO AMBIENTAL COM SUPORTE NAS TECNOLOGIAS DIGITAIS DE INFORMAÇÃO E COMUNICAÇÃO: UMA PROPOSTA PARA COMPOSIÇÃO DE PLANOS MUNICIPAIS DE SANEAMENTO
}

Cristiane T. C. Oliveira ${ }^{1}$

RESUMO: O presente estudo é parte do Plano Municipal de Saneamento desenvolvido pelo NUCIPA-UFT para o Município de Taipas do Tocantins e foi desenvolvido a partir da reflexão: Como inserir questões ambientais locais e significativas nos currículos formais das Unidades Escolares das redes Municipais $i O$ presente estudo apresentou como principal objetivo propor um curso de formação continuada para professores da Educação Básica articulando a Educação Ambiental, enquanto conteúdo transdisciplinar e um projeto que já vem sendo desenvolvido no Município, o PROUCA-TO. A metodologia proposta objetiva a formação de professores para uso pedagógico de tecnologias a partir da vivência prática da interdisciplinaridade em trabalho articulado entre as questões ambientais localmente relevantes e significativas, conteúdos curriculares específicos de cada área do conhecimento e uso pedagógico de diferentes linguagens mediatizado pelo uso do computador. Para o desenvolvimento desse projeto propõe-se que haja o trabalho de equipe multidisciplinar, para tanto, propõe-se que o poder público local faça parcerias com Institutos de Ciências e Tecnologia, Núcleos de Pesquisa ou com Universidades.

PALAVRAS - CHAVE: Educação Ambiental. Formação de professores para uso pedagógico de tecnologias. Plano Municipal de Saneamento Básico.

\footnotetext{
${ }^{1}$ Aluna de Doutorado do Programa de Pós Graduação em Educação Currículo - PUC SP cristcdoliveira@gmail.com
} 


\section{I- INTRODUÇÃO}

Os problemas ambientais foram criados por homens e mulheres e deles virão as soluções. Estas não serão obras de gênios, de políticos ou tecnocratas, mas sim de cidadãos e cidadãs.

Marcos Reigota

O Projeto de formação de professores para trabalho com Educação Ambiental apresentado nesse estudo é parte de um Plano Municipal de Saneamento Básico desenvolvido pela equipe multidisciplinar de pesquisadores do NUCIPA (Núcleo de Caracterização e Impactos Ambientais) para o Município de Taipas do Tocantins (região sudeste do estado do Tocantins). O Plano envolve proposições e ações que vão desde o levantamento de espécies arbóreas urbanas, até o planejamento da disposição dos dejetos e criação de espaços públicos para o convívio social. Todas as proposições partem do pressuposto da melhoria da condição ambiental, recuperação de áreas degradadas, preservação ambiental e principalmente melhoria na qualidade de vida dos munícipes.

As propostas apresentadas no Plano são consistentes e concretas, envolvendo desde construções de sistemas a capacitação de mão de obra humana para sua manutenção. Mas, para que tais propostas possam de fato representar melhoria na qualidade de vida das pessoas que utilizam os espaços urbanos e que, sobretudo, fazem a vida do município, é imperativo considerar que as questões ambientais locais devem fazer parte da formação das pessoas, pois, segundo Reigota (2009) as pessoas só podem preservar aquilo que conhecem.

Pensando que hoje no Brasil a educação das pessoas passa necessariamente por algum tipo de escolarização, propomos que as informações contidas no Plano sejam incluídas como conteúdos curriculares da educação formal. Assim, questões locais relativas ao meio ambiente, passarão de forma sistemática e interdisciplinar a integrar o currículo escolar.

Reigota (2009) destaca a importância da inserção interdisciplinar da educação ambiental na educação escolar permeando todas as áreas do conhecimento a fim de 
proporcionar outra percepção do mesmo problema sobre a ótica de outra disciplina. A educação ambiental vista assim, poderá ganhar novos significados, garantindo maior articulação entre conteúdos gerais e locais - atribuindo ao conhecimento formal maior significado e embasamento teórico que justifique a preservação, conservação e manutenção das características ambientais locais.

Para que seja viável tal inserção, entendemos que uma questão central é a formação continuada dos professores da Educação Básica, visando o desenvolvimento de um trabalho pedagógico norteado pelas questões ambientais do município e do seu entorno.

A formação continuada dos professores da educação básica - encontra-se entre as prioridades do Ministério da Educação explicitadas no Plano de Desenvolvimento da Educação (PDE), para garantir educação de qualidade, centrada no aprendizado do educando.

A criação da Política Nacional de Formação de Profissionais do Magistério da Educação Básica é uma das respostas a esse compromisso, e foi instituída pelo Decreto 6.755 de 29 de janeiro de 2009, a Política Nacional de Formação de Profissionais do Magistério da Educação Básica, tem por finalidade apoiar, em regime de colaboração entre a União, os Estados, o Distrito Federal e os Municípios, a formação inicial e continuada dos professores das redes públicas da educação básica.

Dentre os princípios da política nacional está a formação docente construída em bases científicas e técnicas sólidas, como compromisso público de Estado. Pretende o Ministério aumentar o número de professores formados por instituições públicas de educação superior e garantir um referencial de qualidade para os cursos de formação inicial e continuada, sintonizando-os às necessidades formativas da educação básica e aos problemas da sala de aula.

Como estratégia de planejamento do apoio técnico e financeiro aos Estados, Municípios e Distrito Federal para o alcance dos compromissos com a qualidade na educação, o MEC instituiu o Plano de Ações Articuladas (PAR), por meio do qual cada uma dessas instâncias consolida suas demandas, entre elas as ações de formação. Também como instrumento de planejamento, o MEC definiu o Catálogo de Cursos de Formação Continuada e criou, em 2012, o PDE Interativo, que possibilitou levantar o 
interesse dos professores, por intermédio da internet, nos cursos de formação oferecidos com base na demanda identificada no PAR. A partir deste levantamento, foi disponibilizada na matriz orçamentária da referida Instituição recursos que viabilizaram este curso.

\section{II- CURSOS ONLINE PARA FORMAÇÃO CONTINUADA DE PROFESSORES}

No Brasil, atualmente, a formação das pessoas passa necessariamente por algum tipo de escolarização, dessa maneira as questões trabalhadas na escola podem ter uma abrangência muito grande do ponto de vista da inserção social. Assim, integrar questões emergentes da vivência dos munícipes ao currículo escolar pode trazer mais do que uma aprendizagem significativa, pode contribuir para o conhecimento sistematizado de questões sociais e ambientais reais, a partir de embasamento teórico científico e da sensibilização dos atores em relação a sua participação para a preservação e recuperação ambiental - entendendo-se como ser agente protagonista de suas ações para a melhoria da qualidade de vida na sua cidade. Reforçando a necessidade apontada por Reigota (2009) de enfatizar o estudo do meio onde vive o aluno, abordando os problemas existentes e as possíveis soluções, envolvendo a comunidade para a solução e melhoria do próprio meio.

Entendemos também que para o sucesso de nossa proposta ela deve ser feita de forma articulada harmonicamente com projetos políticos federais, estaduais, municipais e projetos pedagógicos já desenvolvidos nas escolas, com vistas a otimização de recursos materiais já existentes nas unidades escolares e formações já realizadas. Entendemos que nossa proposta, assim, torna-se viável e exequível.

O município de Taipas tem hoje 3 Unidades Escolares, abrangendo desde a Educação Infantil até o Ensino Médio, sendo elas:

- Creche Municipal Maria Martins (onde é ofertada a Educação Infantil- atendendo a 105 crianças de 0 a 5 anos)

- Escola Municipal Thezilda Sampaio de Oliveira (que oferta as séries iniciais do Ciclo 1 do Ensino Fundamental- $1^{\circ}, 2^{\circ}$ e $3^{\circ}$ anos- atendendo 93 alunos) 
- Escola Estadual Joaquim Francisco de Azevedo (que atualmente atende do $4^{\circ}$ ano do ensino fundamental ao $3^{\circ}$ ano do Ensino Médio- atendendo crianças e jovens)

No primeiro semestre de 2012, o governo do estado do Tocantins adquiriu milhares de Laptops educacionais e um percentual significativo desses equipamentos foi distribuído para diversas Secretarias Municipais de Educação, para que essas de acordo com a política local fizessem o repasse para as escolas componentes de suas redes.

Nesse contexto, Taipas recebeu 80 computadores e repassou as máquinas para a Escola Municipal Thezilda Sampaio de Oliveira, onde a distribuição será feita em agosto de 2013 entre as três séries ofertadas ( $1^{\circ}, 2^{\circ}$ e $3^{\circ}$ anos), visando a utilização por todos os 94 alunos da escola, na perspectiva de um para um de forma compartilhada.

A Universidade Federal do Tocantins (UFT), valendo-se do Decreto 6.755 de 29 de janeiro de 2009, a Política Nacional de Formação de Profissionais do Magistério da Educação Básica, e considerando:

- a aquisição de computadores feita pelo Estado do Tocantins; e

- a necessidade e a importância da formação dos professores para que o uso pedagógico dos Laptops de forma integrada ao currículo escolar possa realmente representar uma melhoria na qualidade da educação oferecida.

Em março de 2013, em parceria com a Secretaria Estadual de Educação, União Nacional do Dirigentes Municipais de Educação, Universidade Federal de Ouro Preto, Pontifícia Universidade Católica de São Paulo e Ministério da Educação, lançou uma chamada pública para que as Secretarias Municipais de Educação contempladas com a doação dos computadores pudessem fazer parte do Projeto de formação de professores PROUCA/TO.

O município de Taipas enviou sua carta de adesão ao PROUCA/TO e a partir de agosto fará parte da formação de professores para uso pedagógico dos Laptops educacionais, cujo objetivo central:

- Capacitar professores e gestores das escolas das redes municipais do estado do Tocantins para o uso pedagógico das TDIC (tecnologias digitais de informação e comunicação), possibilitando assim a inclusão digital escolar, e a apropriação tecnológica e pedagógica das TDIC enquanto linguagem a partir dos Laptops educacionais (PROUCA-TO, 2013, p. 03) 
Entendemos que, a partir do contexto apresentado e do diagnostico levantado em pesquisa de campo, seja possível aproveitar os equipamentos recebidos pela escola e o nível de apropriação tecnológica dos professores - depois da formação de 180h oferecida pela UFT pela qual os professores passarão durante os anos 2013 e 2014-, para proposição e desenvolvimento de novos cursos de formação de professores na modalidade a distância.

Tendo como tema central "Meio Ambiente", tais cursos proporão a utilização dos computadores adquiridos para:

- acesso a conteúdos sobre o tema disponíveis em portais e sites educacionais na rede mundial de computadores, nos mais diversos formatos (textos escritos, filmes de longa e curta metragem, documentários, musicas, poesias, imagens, etc);

- aumentar a exposição tanto dos professores e gestores das escolas, como também dos alunos (crianças, jovens e adultos) e de suas famílias às tecnologias digitais;

- contribuir para inclusão digital dos munícipes de Taipas;

- aumentar o acesso as informações a partir da utilização de bases de dados científicos, visitas a bibliotecas, parques, museus, prédios, programas de TV, radio, etc; mas principalmente como

- elemento estruturante do currículo escolar capaz de articular conhecimentos gerais consagrados com características histórico físicas do município e elementos da cultura local e regional.

\section{III- O TRABALHO DE EDUCAÇÃO AMBIENTAL UTILIZANDO RECURSOS COMPUTACIONAIS}

A proposição de formação continuada de professores para o trabalho com a Educação Ambiental, objetiva também a formação de professores para uso pedagógico de tecnologias a partir da vivência prática da interdisciplinaridade em trabalho articulado entre "Meio Ambiente" (enquanto tema transversal proposto pelos Parâmetros Curriculares Nacionais - PCN), conteúdos curriculares específicos de cada área do 
conhecimento (língua portuguesa, matemática, ciências, história, geografia, artes, língua estrangeira educação física) e uso pedagógico de diferentes linguagens (FilmesImagens- Poesia- Música), mediatizado pelo uso do computador.

Oferecidos na modalidade a distância (EaD), tais cursos poderão também aumentar os níveis de apropriação pedagógica das tecnologias por parte dos professores e gestores, além do potencial de ser um importante elemento de inclusão digital dos alunos e de suas famílias.

Para tanto, poderá ser utilizada a plataforma MOODLE (plataforma livre), por ser um Ambiente Colaborativo de Aprendizagem que utiliza a tecnologia Internet e permite a concepção, administração e desenvolvimento de diversos tipos de ações, como projetos colaborativos e outras formas de apoio a distância e aos processos de ensino e de aprendizagem.

Como conteúdos para os cursos propõem-se a utilização de material online proporcionando uma leitura hipertextual e multimidiática através dos conteúdos disponíveis em portais, e em outros repositórios de conteúdos educacionais da Internet.

Pretende-se que, durante os cursos, os professores tenham oportunidade de construção de novos conhecimentos versáteis e socialmente significativos, articulados com experiências práticas de uso pedagógico e da integração do uso de tecnologias ao currículo vivenciado na escola e a produção de material multimidiático articulando conhecimentos teóricos específicos com conhecimentos não formais vivenciados pelos habitantes da cidade.

A metodologia proposta para a formação de professores inclui o uso de diferentes linguagens, como: filmes, documentários, imagens, poesias, músicas, etc; para tratar o tema central "Meio Ambiente", com a finalidade de:

- Oportunizar maior aproximação entre conteúdos disciplinares específicos, teóricos, científicos e questões cotidianas vivenciadas pelos alunos e pelos próprios professores na cidade;

- Ampliar o conhecimento dos professores sobre educação ambiental e meio ambiente, não só como temas da área das ciências biológicas, mas como conhecimentos interdisciplinares, práticos e fundamentais para o convívio social;

- Ampliar o universo cultural dos professores cursistas; e 
- Apresentar aos professores cursistas uma oportunidade de experiência prática de relação entre os temas transversais e diferentes linguagens.

TRABALHO PEDAGÓGICO A PARTIR DE DIFERENTES LINGUAGENS - O uso de diferentes linguagens para tratar o mesmo tema transversal tem como objetivos: oportunizar maior aproximação entre a sala de aula (com seus conteúdos disciplinares específicos) e o cotidiano; ampliar o universo cultural dos professores cursistas; e apresentar novas oportunidades de experiência de relação entre temas transversais e linguagens diferentes dos textos digitados.

DESENVOLVIMENTO DE ATIVIDADES EM DIFERENTES AREAS ESPECÍFICAS DO CONHECIMENTO - As atividades têm o objetivo de trazer para a discussão do tema transversal os conteúdos disciplinares de cada área específica, possibilitando ao professor cursista a experiência de vivenciar enquanto aluno possibilidades interdisciplinares, tendo como eixo central o tema "Meio Ambiente".

OFICINAS- As oficinas propostas têm o objetivo de oferecer aos professores cursistas um conhecimento prático articulado com as teorias tratadas durante o curso, visando oportunizar ao professor cursista oportunidade de autoria da própria prática de colocar em prática alguns conhecimentos a princípio apresentados pelos materiais online.

PRODUTO FINAL DO TRABALHO COM DIFERENTES LINGUAGENS - A geração dos produtos a partir do estudo do tema com o auxilio de diferentes linguagens tem como principal objetivo criar oportunidades para que o professor, orientado pela equipe pedagógica, possa planejar suas atividades docentes integrando o uso de diferentes tecnologias e linguagens aos conteúdos curriculares específicos da disciplina que ministra, tendo como pano de fundo o tema transversal "Meio Ambiente", e envolvendo a comunidade externa a escola.

EXEMPLO DE CURSO DE FORMAÇÃO DE PROFESSORES: EDUCAÇÃO AMBIENTAL NA ESCOLA: O TRABALHO PEDAGÓGICO A PARTIR DO USO DE MULTIMEIOS TEMA GERADOR: MEIO AMBIENTE Caros cursistas, 


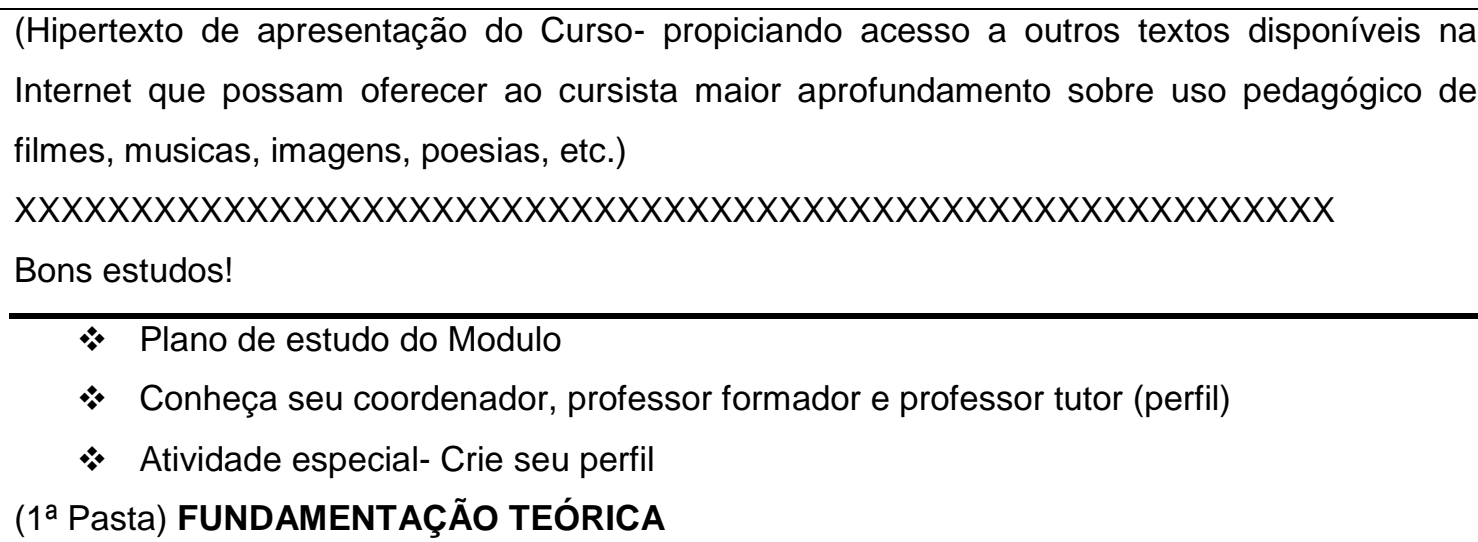
Internet que possam oferecer ao cursista maior aprofundamento sobre uso pedagógico de filmes, musicas, imagens, poesias, etc.)

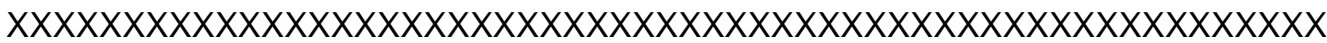

Bons estudos!

\section{Programas disponíveis -}

-Material online sobre possibilidades de uso pedagógico de filmes, musicas, imagens, poesias, etc.-

-Material online sobre "Meio Ambiente"- embasamento teórico sobre o tema a partir da vertente de educação ambiental como principio de convívio social. Vídeos- Programas, documentários ou entrevistas disponíveis na Internet (exemplo de repositório: no Portal da TV Escola (sala de professor/ fascículos/salto para o futuro), programas disponíveis online pela TV Futura, TV Brasil, TV Cultura, etc....)

Textos - Textos, Hipertextos e Artigos de Apoio (Biblioteca Virtual do curso) - sobre possibilidades de uso pedagógico de filmes em sala de aula (exemplo de repositório online: scielo, domínio público, sites de universidades, revistas científicas online)

Modelo de roteiro para leitura de Filmes/documentários- produzido pela equipe pedagógica de coordenação do curso.

Filmes e documentários- Link para filmes e documentários indicados para trabalho com o Tema Meio Ambiente (exemplo de repositório: Programa Acervo da TV Escola) - propõe-se que sejam indicados tanto filmes consagrados (grandes produções internacionais) como produções nacionais e regionais ou locais, afim de possibilitar a valorização da realidade local de forma articulada as realidades mais distantes e gerais

Apesar da importância da fundamentação teórica e do contato com os diferentes tipos de textos para o trabalho com o tema, nesse modelo de formação de professores, as propostas de atividades ganham posição de destaque, pois, serão elas o centro da discussão sobre a interdisciplinaridade e também o momento inicial para sinalizar a importância da troca de informações e vivências entre os cursistas para a proposição de projetos de intervenção ao currículo da escola. 
Nesse curso de formação as atividades são propostas compondo diferentes pastas no AVA e sempre sucedidas por discussões, orientadas por tutores e professores formadores, utilizando a ferramenta Fórum de discussões disponível na plataforma MOODLE (visando a dialogia- numa concepção freireana- entre o s atores participes do curso e a socialização dos conhecimentos de forma assíncrona- garantindo que todos os participantes possam ter acesso as discussões e contribuir com elas independente de estarem online ao mesmo tempo).

- Pasta de atividades 1 - Nessa pasta as atividades serão propostas para cada área específica do conhecimento (língua portuguesa, matemática, ciências, história, geografia, língua estrangeira, educação física, artes), com o objetivo de trazer para a discussão do tema transversal "Meio Ambiente" e os conceitos específicos de cada disciplina, ancorada por diferentes linguagens;

- Pasta de atividades 2 - Nessa pasta as atividades serão propostas pensando seu uso na prática docente cotidiana da sala de aula: como trabalhar determinado filme, ou, o tema com os alunos? Ex.: TEMA X - 2 atividades para sala de aula por área Área da Lingua Portuguesa, Matemática, Ciências Naturais, História, Geografia, Arte, Educação Física, Lingua Estrangeira;

- Pasta de atividades 3 - Nessa pasta as atividades serão propostas pensando o cotidiano escolar e atividades envolvendo não apenas uma sala, mas a comunidade escolar como um todo. É um momento de inserção de atividades práticas no currículo da escola como um todo;

- Pasta de atividades 4 - ATIVIDADE CINEMA DA ESCOLA- Essa é a atividade final do curso, consiste em exibições públicas de filmes selecionados pelos professores (sessões de cinema abertas a comunidade- um cine clube), e apresenta diferentes objetivos de acordo com os atores sociais envolvidos:

1. Primeiro, poderá ser uma oportunidade de as atividades e discussões que ocorrem no cerne da escola extrapolarem o ambiente escolar e envolverem a comunidade local como um todo;

2. Segundo, poderá ser um meio de divulgação sobre as questões ambientais locais;

3. Terceiro, poderá representar um momento de discussões entre diferentes atores sociais, como parte da comunidade e das decisões municipais; 
4. Quarto, poderá representar uma opção de entretenimento, um importante momento de lazer para a comunidade local que não atualmente não desfruta de muitas opções de lazer, principalmente os jovens cidadãos- Assim, a atividade poderá, de certa forma, contribuir para que o poder público garanta aos munícipes, aos cidadãos, o direito constitucional ao Lazer (constituição Brasileira de 1988) sendo uma mais uma alternativa com foco na melhoria da qualidade de vida dos cidadãos.

A proposição das diferentes atividades deverá sempre considerar a importância do ato da pesquisa e da busca por informações, principalmente em base digital, para a construção de conhecimentos socialmente significativos, articulando os conteúdos disciplinares e produções nacionais e internacionais com a realidade local, vivenciada e compartilhada pelos munícipes.

As atividades deverão estimular o uso qualificado de conteúdos educacionais disponíveis na Internet, conforme exemplo:

(pasta) ATIVIDADES 1

1 Língua Portuguesa (1 questão relacionado o conteúdo da disciplina específica ao tema trabalhado no filme)

2 Matemática (1 questão relacionado o conteúdo da disciplina específica ao tema trabalhado no filme)

3 Ciências (1 questão relacionado o conteúdo da disciplina específica ao tema trabalhado no filme)

4 História (1 questão relacionado o conteúdo da disciplina específica ao tema trabalhado no filme)

5 Geografia (1 questão relacionado o conteúdo da disciplina específica ao tema trabalhado no filme)

6 Artes (1 questão relacionado o conteúdo da disciplina específica ao tema trabalhado no filme)

7 Educação física (1 questão relacionado o conteúdo da disciplina específica ao tema trabalhado no filme)

FORUM 1: SOBRE DIFICULDADES ENCONTRADAS NO DESENVOLVIMENTO DAS ATIVIDADES

No fórum 1 o cursista deverá socializar suas dificuldades e êxitos no desenvolvimento das atividades de cada área específica; (discussão sobre as atividades das diferentes áreas e tirar dúvidas com os professores Formadores- orientados pelos professores tutores presenciais)

(pasta) ATIVIDADES 2- SOBRE OS FILMES 
Atividades acompanhadas com texto teórico de apoio, sobre narrativas e usos de audiovisual na sala de aula. Links para alguns exemplos disponíveis no portal Tv escola. Apresentar atividades elaboradas e relacionadas a um filme ou documentário do portal.

Exemplo:

1 Escolha um assunto do seu interesse, um tema ou um fenômeno da natureza (a partir de um audiovisual do Portal da Tv Escola).

Pesquise e contribua com uma definição e entendimento sobre esse assunto: um conceito, uma analogia, uma metáfora, um texto científico, não- científico, ou imagem representativa para cada categoria abaixo.

Das ciências PRINCIPAIS

MATEMÁTICA/FÍSICA/QUÍMICA/BIOLOGIA/HISTÓRIA/GEOGRAFIA

Outras perspectivas do entendimento humano :

JORNALÍSTICA/TEOLÓGICA/FILOSÓFICA/MITOLÓGICA/ANTROPOLÓGICA/CULTURAL/LITE RÁRIA/MÁXIMAS-FRASES

Representações Artísticas :

POESIA/FÁBULAS/MÚSICA/ESCULTURA/PINTURA/FOTOGRAFIA

Obs.: Tudo isso vai servir como projeto e possível roteiro para atividade de construção/produção de Hipertexto e Audiovisual

2 Seguindo o tema e o filme escolhido elabore 2 atividades para cada Área do conhecimento.

FORUM 2: SOBRE OS FILMES

No fórum 2 o cursista deverá postar um texto de no máximo duas páginas socializando suas experiências, dificuldades e êxitos no desenvolvimento das atividades. Deve também contribuir comentando as experiências dos colegas.

(pasta) ATIVIDADE 3- PRÁTICA DE INTEVENÇÃO NO CURRICULO

\section{PRODUTO DO TRABALHO COM A LINGUAGEM FILMICA- IMPLANTAÇÃO DA COLETA SELETIVA NA ESCOLA}

-Juntamente com seus alunos- a partir de uma lista pré- selecionada de material (filmes e documentários) sobre o que é, como se faz e exemplos de experiências de implantação de coleta seletiva em unidades escolares-, faça um levantamento no acervo no Portal da TV Escola, buscando materiais que melhor trate o tema.

- Faça o planejamento de uma unidade de sua disciplina contemplando a "Coleta Seletiva" como texto problematizador das atividades subsequentes.

- Utilizando "Kits" vendidos por empresas especializadas, estabeleça com a equipe de gestão da escola o 
melhor espaço para instalação de coleta e separação do lixo produzido na unidade escolar.

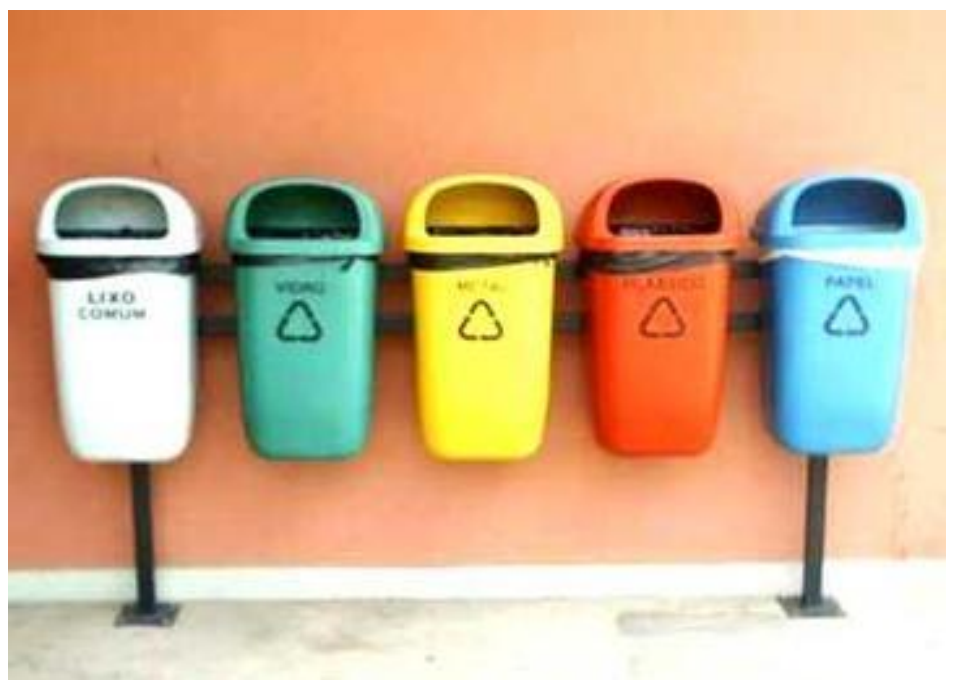

- Oriente seus alunos, separados e grupos, a utilizarem os Laptops educacionais para levantarem informações sobre separação do lixo residencial. Eles deverão, a partir das informações levantadas, produzir: um manual simples para orientação de suas famílias sobre a forma de separação do lixo produzido em casa, a necessidade do material reciclável ser lavado antes de ser descartado, o conceito dos "3 Rs",etc; e cartazes explicativos sobre a separação do lixo residencial. Essas atividades irão contribuir para a informação e consciência da população sobre a importância da coleta seletiva no município.

-Relate suas experiências em um artigo conforme o modelo disponível no AVA e compartilhe com seus colegas publicando no fórum 3.

FORUM 3: RELATO DA EXPERIÊNCIA DA IMPLANTAÇÃO DA COLETA SELETIVA NA ESCOLA.

Envio de artigo (conforme o modelo disponível no AVA), socialização das experiências, trocas e discussão com o grupo- colegas, professores tutores, e professores formadores.

(pasta) ATIVIDADE - CINEMA DA ESCOLA

-Juntamente com seus colegas professores e a equipe de gestão da unidade escolar, organize uma sessão de exibição pública de filmes tratando do tema central "Meio Ambiente"(poderá ser uma exibição de determinada obra ou um circuito com a exibição de diversos filmes sobre o mesmo tema).

- Após cada exibição faça uma roda de discussões sobre o tema, convidando professores de diferentes disciplinas e pessoas da comunidade externa a unidade escolar para discutir os elementos apresentados nos filmes articulando-os a realidade local do município.

ENVIO DE TAREFA (artigo produzido a partir experiência prática - discutido no fórum 2. Após discussões 
com o grupo no Fórum 2 o professor envia o texto definitivo do artigo para avaliação)

As discussões teóricas visarão provocar reflexões nas e sobre as práticas pedagógicas dos professores/cursistas, buscando o estabelecimento de uma estreita vinculação entre conteúdos específicos curriculares de cada disciplina, temas transversais apresentados nos PCN e os dilemas do cotidiano (apresentados e trabalhados em diferentes linguagens).

Outro elemento importante nessa proposta é o registro das atividades, seja na forma da produção de textos ao final de cada atividade, seja na filmagem das oficinas, palestras e discussões originadas nos encontros presenciais (propomos que sejam feitos 4 encontros presenciais durante o curso- nesses momentos serão propostas palestras, oficinas, mesas redondas e discussões sobre a temática).

O registro das atividades, seu desenvolvimento, o registro de experiências e impressões dos cursistas irá, durante o curso, compor um importante acervo de conteúdos para as unidades escolares. A produção desses conteúdos será parte fundamental do curso, pois tais conteúdos serão produzidos a partir de rica experiência prática de dialogo:

- entre os professores cursistas e os textos trabalhados nos cursos (sejam eles grafados, fílmicos, musicados, etc);

- entre os professores cursistas e a equipe pedagógica do curso de formação; entre os próprios cursistas;

- entre os cursistas e os gestores de sua, ou de outras, unidades escolares;

- entre as unidades escolares do município; entre a comunidade escolar e o poder publico local; entre os cursistas e seus alunos nas escolas;

- entre os cursistas e demais membros da comunidade externa a escola.

Entendemos que os conteúdos gerados a partir desses conhecimentos socialmente construídos de forma dialógica, colaborativa e compartilhada, são registros que trazem em si a relevância social, são conhecimentos construídos de forma compartilhada e por isso relevantes e significativos.

\section{IV- OFICINAS PARA PRODUÇÃO DE BRINQUEDOS EDUCATIVOS NA ESCOLA}


Propomos que a partir da inserção da coleta seletiva na escola e da produção de materiais informativos produzidos pelos próprios alunos, a equipe de gestão da escola organize oficinas abertas a comunidade.

Publico alvo- professores, alunos e comunidade geral,

Objetivos - produção de brinquedos educativos a partir da reutilização de materiais recicláveis descartados (reforçando o conceito de "reduzir o consumo, reutilizar e reciclar").

\section{V- ATELÊ PARA PRODUÇÃO DE BRINQUEDOS EDUCATIVOS NA ESCOLA}

Entendemos que é muito importante informar, instruir, sensibilizar e contribuir para que a população local desenvolva consciência ambiental, perceba seu lugar no ambiente e sua participação para manutenção e recuperação da qualidade ambiental e sobretudo qualidade de vida. Por esse viés, a coleta seletiva, e a conscientização da produção de resíduos devem caminhar juntas.

As oficinas propostas poderão contribuir muito para esse desenvolvimento de consciência, no entanto é preciso pensarmos em um próximo passo, não basta ensinar a população a produzir novos materiais a partir de material descartado, entendemos a relevância de se dar volume e utilidade a essa produção.

Assim, a proposta se completa com a ideia de montar um ateliê de produção de brinquedos educativos. Sugerimos para o funcionamento do ateliê:

\begin{tabular}{|l|l|}
\hline Espaço & Finais de semana- Pátio da Escola Municipal \\
\hline Pessoal & Voluntários que tenham habilidades para trabalho manual \\
\hline Matéria prima & $\begin{array}{l}\text { Material reciclável descartado, devidamente lavado. Produzido e coletado } \\
\text { na comunidade. Materiais custeados pela Prefeitura Municipal }\end{array}$ \\
\hline Produtos produzidos & $\begin{array}{l}\text { Os brinquedos produzidos serão doados para compor o acervo de uma } \\
\text { Brinquedoteca Pública, que poderá funcionar na Creche Municipal }\end{array}$ \\
\hline
\end{tabular}

Uma vez tendo uma brinquedoteca com um acervo interessante os brinquedos produzidos poderão também ser doados, periodicamente às crianças da cidade.

Nesse espaço, as pessoas podem trocar experiências e desenvolver sua criatividade na elaboração e confecção de outras peças que não apenas brinquedos, mas 
peças de utilidade doméstica, de decoração, etc, de acordo com o que a criatividade e a imaginação permitirem. $O$ ateliê, além de um espaço de produção poderá cumprir também a função de convívio social e de lazer para os munícipes.

Para o desenvolvimento desse projeto de formação de professores, propõe-se que haja o trabalho de equipe multidisciplinar composta por pedagogos (com reconhecida formação e experiência em novas tecnologias na educação e educação ambiental), e profissionais com reconhecida atuação na área da educação ambiental, como: biólogos (com experiência docente), engenheiros, químicos, geógrafos e arquitetos (especialistas em estudos sobre as cidades e com comprovada experiência na área da educação). Para tanto, o poder publico local poderá fazer parcerias com Institutos de Ciências e Tecnologia, Núcleos de Pesquisa ou com Universidades.

\section{REFERÊNCIAS}

ALMEIDA, F. J. Computador, escola e vida. São Paulo: Cubzac, 2007.

BRASIL Política Nacional de Formação de Profissionais do Magistério da Educação Básica. Decreto 6.755 de 29 de janeiro de 2009. disponível em: http://www.planalto.gov.br/ccivil 03/ ato2007-2010/2009/Decreto/D6755.htm

Secretaria de Educação Fundamental. Parâmetros Curriculares Nacionais: introdução aos parâmetros curriculares nacionais. MEC/SEF. Brasília, 1997. disponível em: http://portal.mec.gov.br/seb/arquivos/pdf/livro01.pdf

FAZENDA, I. C. A. Interdisciplinaridade: um projeto em parceria. 6ª Ed. São Paulo: Edições Loyola, 2007.

FREIRE, P. Conscientização- Teoria e Prática. São Paulo: Centauro,1981.

OLIVEIRA, C. T. C. de Apropriação tecnológica do docente da educação profissional na modalidade a distância. Dissertação de Mestrado em Educação: currículo. Pontifícia Universidade Católica de São Paulo, 2012.

PROUCA-TO. Palmas, 2013

REIGOTA, M. O que é educação ambiental. 2ª ed. São Paulo: Brasiliense, 2009. 